\title{
Self-Regulatory Imagery and Physical Activity in Middle-Aged and Older Adults: A Social-Cognitive Perspective
}

\author{
Maria-Christina Kosteli, Jennifer Cumming, and Sarah E. Williams
}

\begin{abstract}
Limited research has investigated exercise imagery use in middle-aged and older adults and its relationship with affective and behavioral correlates. The study examined the association between self-regulatory imagery and physical activity (PA) through key social cognitive variables. Middle-aged and older adults $(N=299 ; M$ age $=59.73$ years, $S D=7.73$, range $=50$ to 80$)$ completed self-report measures assessing self-regulatory imagery use, self-efficacy, outcome expectations, perceived barriers, self-regulatory behavior, enjoyment, and PA levels. Path analysis supported a model $\left(\chi^{2}[14]=21.76, p=.08, \mathrm{CFI}=.99\right.$, $\mathrm{TLI}=.97, \mathrm{SRMR}=.03, \mathrm{RMSEA}=.04)$ whereby self-regulatory imagery positively predicted self-efficacy, outcome expectations, and self-regulatory behaviors. Furthermore, self-regulatory imagery indirectly predicted barriers, outcome expectations, self-regulation, enjoyment, and PA. This research highlights self-regulatory imagery as an effective strategy in modifying exercise-related cognitions and behaviors. Incorporating social cognitive constructs into the design of imagery interventions may increase PA engagement.
\end{abstract}

Keywords: exercise imagery, social cognitive theory, self-efficacy, enjoyment, self-regulation

Physical activity (PA) can prevent many of the negative outcomes associated with aging such as bone loss, risk of cardiovascular disease, and arthritis (Shephard, 1997). It also induces many positive psychological outcomes such as improved mental health and mood (Sonstroem, Harlow, \& Josephs, 1994). Despite its significant health benefits, the majority of middle-aged and older adults do not engage in sufficient levels of PA, and these levels continue to decline with age (Besson et al., 2009). Therefore, techniques to enhance PA in middleaged and older adults are imperative to ensure healthy aging. However, it is important to first understand the key determinants of PA behavior in this population, and how techniques that can increase PA relate to the different determinants.

One of the most popular theories used to explain PA behavior in middle-aged and older adults is social cognitive theory (SCT; Bandura, 1997), which refers to the social and cognitive factors that determine human motivation, including but not limited to selfefficacy (belief in one's ability to engage in a particular task and achieve an outcome), barriers (factors that prevent individuals from being active), outcome expectations (benefits people expect from participation to PA), and self-regulatory behavior (skills necessary to regulate behavior). Previous research found that social cognitive factors accounted for 55\% of the variance in PA in young adults and $52 \%$ of the variance in PA in retired middle-aged and older adults (Rovniak, Anderson, Winett, \& Stephens, 2002; Schuster,

(C)2018 The Authors. Published by Human Kinetics, Inc. This is an Open Access article distributed under the terms of the Creative Commons Attribution License CC BY 4.0, which permits unrestricted noncommercial and commercial use, distribution, and reproduction in any medium, provided the original work is properly cited, the new use includes a link to the license, and any changes are indicated. See https://creativecommons.org/licenses/by/4.0/. This license does not cover any third party material which may appear with permission in the article.

Kosteli is with the Department of Sport and Physical Activity, Edge Hill University, Ormskirk, United Kingdom. Cumming and Williams are with the School of Sport, Exercise and Rehabilitation Sciences, University of Birmingham, Birmingham, United Kingdom. Address author correspondence to Maria-Christina Kosteli at kostelim@edgehill.ac.uk.
R. Petosa, \& Petosa, 1995). Thus, SCT appears to be an important framework to underpin interventions promoting PA in middle-aged and older adults. Each of the social-cognitive constructs is associated to PA behavior to varying degrees, with self-efficacy being one of the strongest predictors (McAuley, 1993).

Previous research with older adults has indicated that overall increases in self-efficacy are associated with more engagement in PA (Conn, 1998). Specifically, feeling confident in one's ability to overcome exercise-related barriers, referred to as barrier selfefficacy, influences the frequency and the intensity of exercise participation in middle-aged adults (McAuley, 1992), as well as the number of barriers perceived, which is another social-cognitive variable. Studies show that there is a strong relationship between barriers and PA, with more perceived barriers related to lower levels of PA (Salmon, Owen, Crawford, Bauman, \& Sallis, 2003). This is especially true for older exercisers who tend to report low levels of PA because of the high number of barriers they face (Kosteli, Williams, \& Cumming, 2016).

Similarly, outcome expectations can be predictive of exercise behavior, with higher outcome expectations related to higher levels of PA (Schwarzer \& Fuchs, 1995). Expecting positive outcomes, such as health benefits, is thought to facilitate engagement in PA (Mathews et al., 2010). In a study with younger adults, Rovniak et al. (2002) found that outcome expectations did not directly predict PA and had a small total effect on PA. This finding is consistent with other research, which has shown that the relationship between outcome expectations and PA is primarily indirect through selfregulation (Ayotte, Margrett, \& Hicks-Patrick, 2010). This indirect relationship could be explained by the fact that middle-aged and older adults are not likely to engage in PA if they do not have the strategies in place to self-regulate their behavior (Bandura, 1997).

Self-regulation refers to the goals and plans middle-aged and older adults set to manage their behavior (Luszczynska, Diehl, Gutiérrez-Doña, Kuusinen, \& Schwarzer, 2004). It can also predict PA behavior both directly and indirectly (Anderson, Wojcik, Winett, \& Williams, 2006; Ayotte et al., 2010; Umstattd, Wilcox, Saunders, Watkins, \& Dowda, 2008) indicating the importance of 
self-regulation as a strategy to enhance PA. Self-regulation is likely associated with PA through other PA correlates. An intrinsic and affective variable that could mediate the relationship between selfregulation and PA is enjoyment, which can in turn directly predict PA (Salmon et al., 2003). In a recent systematic review, Rhodes and Kates (2015) indicated that experiencing positive feelings during exercise can predict future PA behavior. Thus, enjoyment as an integral part of intrinsic motivation can facilitate involvement in PA (Wankel, 1993). Enjoyment has also been found to be associated with a variety of PA correlates, such as self-efficacy and goal setting (Rovniak et al., 2002). For instance, enjoyment of PA can influence the perceptions of competence for engaging in PA. However, research has yet to determine whether enjoyment relates to socialcognitive variables such as self-regulation, as well as examining the interrelationships between these variables and PA.

More recently, Ayotte et al. (2010) investigated the relationship among the social-cognitive determinants of PA in a group of middleaged and older adults. Self-efficacy expectations related to selfregulatory behavior through their strong association with outcome expectations and perceived barriers. Specifically, higher selfefficacy was associated with more positive outcome expectations and fewer barriers to PA. Self-regulation can impact PA through self-efficacy in both younger and older adult populations (Dishman et al., 2005; Rovniak et al., 2002; Umstattd et al., 2008). Higher selfefficacy is associated with more self-regulatory strategies, which in turn are associated with higher levels of PA. These results indicate that when designing PA interventions, it is important to employ strategies that target these different social-cognitive factors.

A well-known intervention strategy to promote PA is imagery (Hall, 1995). Imagery is defined as the mental representation of an object, action, or psychological state in the absence of any external stimulus and can be used for both cognitive and motivational reasons (Moran, 2009; Paivio, 1985). For example, it could involve imagining yourself performing the exercises in an aerobics class and experiencing positive psychological outcomes such as feeling energetic. Previous research on exercise imagery has indicated that it can be an effective strategy to increase and/or maintain PA levels (Giacobbi, Hausenblas, Fallon, \& Hall, 2003). For example, Chan and Cameron (2012) found that insufficiently active adults who imaged themselves being physically active reported higher levels of PA at the end of the intervention program compared to before. Studies have also tried to explain how imagery leads to higher levels of PA by focusing on the concept of self-efficacy.

Imagery is a well-known source of self-efficacy that can increase motivation and influence PA behavior (Hall, 1995). For instance, imaging oneself completing a workout can enhance one's confidence in their ability to overcome barriers to exercise such as bad weather or fatigue. Thus, imagery can boost self-efficacy (Duncan, Hall, Wilson, \& Rodgers, 2012). Previous research found that participants had higher levels of barrier self-efficacy at the end of an imagery intervention (Weibull, Cumming, Cooley, Williams, $\&$ Burns, 2014). As a result of these increased efficacy beliefs through using imagery, individuals will be more likely to engage in PA (Cumming, 2008). Collectively, these results indicate that there is a relationship between imagery, self-efficacy, and PA. However, research is now needed to examine the relationship between different types of exercise imagery and a fuller complement of social-cognitive variables in middle-aged and older adults.

Exercise imagery research to date has primarily focused on appearance, energy, and technique imagery (Hausenblas, Hall, Rodgers, \& Munroe, 1999). However, qualitative research suggests that older adults can also benefit from using other types of imagery to help them engage in PA (Kosteli, Williams, \& Cumming, 2017). For instance, older adults frequently used images of achieving the goals they set (e.g., imaging exercising to lose weight and achieving the goal of losing weight) to motivate themselves to exercise. This is in support of previous research that has shown that goal-oriented imagery can increase PA by motivating individuals not only to pursue their goals but also to commit and extend more effort to achieve their goals (Chan \& Cameron, 2012; Schultheiss \& Brunstein, 1999). Consequently, goal imagery likely represents part of the self-regulatory behavior and is considered to be an important determinant of PA. Planning imagery is another component of self-regulatory behavior that would also be worth investigating. Kosteli et al. (2016) found that older adults value the importance of committing to an exercise routine and use planning to help them engage in PA (e.g., set a time to exercise). Based on the potential for self-regulation to promote PA in older adults (Purdie \& McCrindle, 2002), a new type of imagery consisting of planning and goal setting is proposed in the present study named self-regulatory imagery. This concept includes images of keeping to a schedule; the planning, engagement, and achievement of exercise plans and goals as well as the plans and goals themselves; and the feeling of motivation as a result of them. To our knowledge, research has yet to investigate whether self-regulatory imagery can be an effective intervention tool to promote PA in middle-aged and older adults and examine the pathways through which this type of imagery is related to PA.

Therefore, the aim of the present study was to explore whether self-regulation imagery is related to middle-aged and older adults' PA through its relationship with social-cognitive variables, and affective states. Based on the existing literature and Paivio's (1985) $2 \times 2$ conceptual framework of imagery, it was hypothesized that greater self-regulatory imagery use would positively predict PA behavior, as images of achieving exercise plans and goals would serve a motivational-specific function. It was also hypothesized that self-efficacy would mediate the relationship between selfregulatory imagery and self-regulatory behavior while perceived barriers and outcome expectations would mediate the relationship between self-efficacy and self-regulatory behavior. Furthermore, it was hypothesized that self-regulatory behavior and enjoyment would mediate the relationship between imagery and PA. Understanding the relationship between self-regulatory imagery and other social-cognitive variables may lead to better insight on which variables to target when designing imagery interventions while at the same time providing evidence to support using self-regulatory imagery as an intervention tool for middle-aged and older adults.

\section{Method}

\section{Participants}

Three hundred and twelve male $(n=168)$ and female $(n=144)$ middle-aged and older adults ranging in age from 50 to 80 years ( $M$ age 59.73; $S D=7.73$ ) took part in the study. We sought to include individuals who were healthy with no known cognitive impairments, and able to speak and read English. Most participants $(n=296)$ were White with the remaining participants being Asian $(n=6)$, from a multiple ethnic group $(n=2)$, or choosing not to report their ethnicity $(n=7)$. Participants had different perceptions about their health (assessed on a 5-point Likert scale from $1=$ Poor to $5=$ Excellent) ranging from poor $(n=5)$, fair $(n=13)$, good $(n=79)$, very good $(n=128)$, and excellent $(n=87)$. All participants confirmed that they conformed to the inclusion criteria and, on average, participants reported having good health. 


\section{Measures}

Demographic information. Participants provided information regarding their age, sex, ethnicity, and their perceived health status.

Imagery use. For the present study, 12 items were developed to represent self-regulatory imagery (see Appendix 1). Based on previous research that acknowledges self-regulation as a unidimensional concept consisting of planning and goal setting (Luszczynska et al., 2004), in the current study one imagery factor was originally developed with six items representing planning (e.g., "I imagine keeping to my plans for exercising") and six items representing goal-setting (e.g., "I imagine the exercise goals I have set"). The new self-regulatory imagery dimension created can be used to complement existing validated questionnaires and can contribute to a better conceptualization of the different exercise imagery types. These self-regulatory items were initially reviewed by an expert panel, composed of seven researchers experienced in imagery research and were deemed appropriate and easy to imagine. Item wording was based on the format of the Exercise Imagery Inventory-Revised (EII-R; Giacobbi, Hausenblas, \& Penfield, 2005), which assesses appearance-health, technique, self-efficacy, routine, and feelings exercise imagery. Similarly to the EII-R, responses to all items were made on a 7-point scale ranging from 0 (never/rarely) to 6 (always). However, to match the EII-R scale, during data entry the scale was converted from 1 (never/rarely) to 7 (always). Prior to completing the items participants were provided with a description of exercise imagery similar to the one provided in previous qualitative studies (Giacobbi et al., 2003):

Imagery involves mentally seeing yourself exercising. The image in your mind should approximate the actual physical activity as closely as possible. Imagery may include sensations like hearing the aerobic music and feeling yourself move through the exercises. Imagery can also be associated with emotions (e.g., getting psyched up or energized), staying focused (concentrating on an aerobic class and not being distracted), setting exercise plans/goals (e.g., imaging achieving a goal of losing weight), etc.

This definition of imagery was deemed appropriate for this age group as it was field tested prior to data collection with older adults of a similar age.

Self-regulation. Self-regulation was measured using the Exercise Planning and Scheduling Scale (EPS; Rovniak et al., 2002) and the Exercise Goal-Setting Scale (EGS; Rovniak et al., 2002). Similar to past research (Elavsky, Doerksen, \& Conroy, 2012) a total selfregulation score was computed by taking the average of both scales with a higher score indicating higher self-regulation. The EPS and EGS each represent a 10-item scale assessing how participants plan and schedule PA (e.g., 'I schedule my exercise at specific times each week) and how they go about setting PA goals (e.g., 'I usually set dates for achieving my exercise goals'), respectively. Participants indicate how well each item describes them on a 5-point Likert-type scale from 1 (does not describe me) to 5 (describes me completely). Both questionnaires are valid and reliable measures of self-regulation (Elavsky et al., 2012).

Outcome expectations. The Outcome Expectations for Exercise Scale (OEES; Resnick, Zimmerman, Orwig, Furstenberg, \& Magaziner, 2000) is a nine-item scale on which participants indicate how they feel about exercise by rating how strongly they agreed with each of the nine positive outcomes of PA (e.g., 'makes me feel better physically'). Responses are made on a 5-point Likert-type scale $(1=$ strongly disagree, to $5=$ strongly agree). After certain items are reversed, responses are averaged across the nine items so that a higher score represents greater outcome expectancies. The OEES is a valid and reliable measure of outcome expectations (Resnick et al., 2000).

Barriers. The Perceived Barriers to Exercise (PBE; Salmon et al., 2003 ) is an 18-item scale on which participants rate how much certain barriers (e.g., cost, age, lack of time) prevent them from engaging in PA. Responses to each barrier are made on a 5-point Likert-type scale $(1=i$ s not a barrier to $5=$ very much a barrier $)$. Responses are averaged across the 18 items so that a higher score indicates greater barriers to exercise. This PBE is a valid and reliable measure (Salmon et al., 2003).

Barriers self-efficacy. The 13-item Barriers Specific Self-Efficacy Scale (BSSES; McAuley, 1992) assessed participants' beliefs that they could exercise three times a week for the next 3 months in the face of certain barriers (e.g., bad weather, pain, tiredness). Responses to the items ranged on an 11-point scale from $0 \%$ (not at all confident) to $100 \%$ (very confident). Items were averaged so that a higher score represented a higher barrier efficacy. The BSSES is a valid and reliable measure (McAuley, 1992, 1993).

Interest-enjoyment. The Interest-Enjoyment Subscale from the Intrinsic Motivation Inventory (IES; Ryan, 1982) is a 7-item scale, which assesses participants' enjoyment of exercise participation. Participants indicate how much they agree or disagree with each statement on a 7-point Likert-type scale ranging from 1 (not at all) to 7 (extremely). Responses are averaged so that a higher score indicates greater enjoyment. The IES is a valid and reliable measure of enjoyment (McAuley, Duncan, \& Tammen, 1989).

Physical activity. Participants' PA levels were assessed with the International Physical Activity Questionnaire (IPAQ; Craig et al., 2003). Participants reported how often in the last week they engaged in walking, moderate, and vigorous PA for at least 10 min. A metabolic equivalent (MET) score was calculated using the following equation: $(3.3 \times$ walking minutes $\times$ walking days $)+$ $(4.0 \times$ moderate-intensity activity minutes $\times$ moderate days $)+(8.0 \times$ vigorous-intensity activity minutes $\times$ vigorous-intensity days). According to the guidelines total scores can range from 600 MET$\mathrm{min} /$ week representing minimally active individuals to 3,000 MET-min/week and above representing high active individuals. However, the classification of individuals in categories depends on the combination of intensity and frequency of PA. For instance, individuals engaging in vigorous-intensity activity on at least 3 days/week and accumulating at least 1,500 MET-min/week would also classify in the high active category. The IPAQ has been identified as a valid and reliable measure of PA in 12 countries with good psychometric properties (Booth et al., 2003).

\section{Procedures}

After ethical approval from the university where the authors are based, participants were recruited through word of mouth, posters, and social media. Individuals interested in participating in the study were provided with an information sheet outlining the nature of the study. To ensure that older adults understood the concept of "mental imagery", the same term was consistently used throughout the study and a definition of it was also provided in the information sheet. The information sheet described mental imagery as being, "An experience you can create or re-create in your mind using your 
different senses (e.g., seeing yourself going for a walk and how it feels to move your body). It is a popular strategy used by active or inactive individuals to learn exercise tasks, become energized, set appearance goals and cope with exercise barriers." After they were provided with this imagery description, participants were asked to reflect their understanding and were given the opportunity to ask questions in case they were unclear. Participants were informed that participation was voluntary, they were free to withdraw at any time without giving reason, and their confidentiality would be maintained. Participants willing to participate provided written consent and their contact information (address or email) so that they could receive a questionnaire pack. Participants then completed either a hard copy or electronic copy of the questionnaire pack (depending on their preference), which took no longer than $30 \mathrm{~min}$. Completed hard copies were returned to the researcher in a prepaid envelope. All participants were thanked for their participation.

\section{Data Analysis}

Data were screened for missing values and outliers according to the recommendations of Tabachnick and Fidell (2001). Univariate and multivariate normality (i.e., skewness and kurtosis) was then examined. An exploratory confirmatory factor analysis (CFA) using AMOS 22.0 (Arbuckle, 2012) with the bootstrapping technique was then conducted to determine the factor structure of the self-regulatory imagery items. The chi-squared likelihood statistic ratio $\left(\chi^{2} ;\right.$ Jöreskog \& Sötbom, 1993) was used to test the model's overall goodness of fit along with other commonly reported fit indices standardized root mean square residual (SRMR), Tucker Lewis index (TLI), comparative fit index (CFI), and root mean square error of approximation (RMSEA) following $\mathrm{Hu}$ and Bentler's recommendations (1999). To determine acceptable model fit the following guidelines were followed: (a) SRMR (Bentler, 1995) values of $\leq .08$; (b) RMSEA (Kline, 2011) values S.06; and (c) CFI (Browne \& Cudeck, 1992) and TLI (Bollen, 1989) values $\geq$.95. Problematic items were removed in a step-by-step process to improve the model fit by examining the modification indices and factor loadings of subsequent analysis. Once the final set of imagery items had been established, means, standard deviations, internal reliabilities, correlations, and multicollinearity of all study variables were established. Separate 2 sex (male, female) $\times 2$ age groups ( 50 to 64,65 to 80 ) factorial ANOVAs were then conducted to examine any differences in any of the study variables.

To test the hypothesized model, driven by SCT, path analysis was conducted using AMOS 22.0 software and the same model fit criteria as described above. As a way to assess the indirect effects and establish whether mediation exists, the bootstrapping approach was followed (Preacher \& Hayes, 2008). Mediation analysis was conducted based on the recommendations of Hayes (2013) for testing indirect effects. Bootstrapping of 2,000 samples was used as it has been recommended to provide more accurate confidence intervals (Efron \& Tibshirani, 1994). To control for age and sex, these variables were entered into all path analyses.

\section{Results}

\section{Missing Data and Outliers}

There were no variables with $>5 \%$ missing values. Overall, $0.9 \%$ of the data were missing. The Little missing completely at random (MCAR; Tabachnick \& Fidell, 2001) test was nonsignificant $\left(\chi^{2}=392.87, d f=377, p>.05\right)$, indicating that there was no significant deviation from a pattern of values that are missing completely at random. Nine cases were deleted because of missing an entire measure or most of a measure. Missing values in the remaining cases $(N=303)$ were imputed using the expectation maximization (EM) algorithm (Enders, 2006). Two multivariate outliers were identified $(p<.01)$ using Mahalanobis distance as well as two univariate outliers $(z>3.29)$. Thus the four outliers were removed from the dataset leaving a final sample of 299 participants.

\section{Confirmatory Factor Analysis}

The aim of the exploratory CFA was to identify the best set of items representing the unidimensional concept of self-regulatory imagery. When examining the factor structure of the 12 imagery items, the single factor solution yielded an adequate fit to the data, $\chi^{2}(54)=298.03, p<.001, \mathrm{CFI}=.93, \mathrm{TLI}=.91, \mathrm{SRMR}=.04$, $\mathrm{RMSEA}=.12(90 \% \mathrm{CI}=0.11-0.14)$. Inspection of the modification indices revealed two problematic items, which were deleted. The second and third run factor solutions were improved but highlighted three problematic items as illustrated by the modification indices and thus removed. In the fourth run, a 7-item single factor solution yielded a much improved fit to the data, $\chi^{2}(14)=$ $37.896, p=.001, \mathrm{CFI}=.99, \mathrm{TLI}=.98, \mathrm{SRMR}=.02, \mathrm{RMSEA}=.08$ (90\% CI $=0.08-0.10)$. However, the factor loading of one item was lower than the recommendations and was deleted from the model (Hair, Black, Babin, Anderson, \& Tatham, 2006). In the fifth and final run, an adequate fit to the data was established for the six-item one-factor model consisting of three planning items and three goal items, $\chi^{2}(9)=23.36, p=.005, \mathrm{CFI}=.99, \mathrm{TLI}=.98, \mathrm{SRMR}=.02$, $\mathrm{RMSEA}=.07(90 \% \mathrm{CI}=0.04-0.11)$ with all factor loadings, modification indices, and standardized residuals within acceptable limits and no offending estimates existed in the data (Hair et al., 2006).

\section{Descriptive Statistics, Intercorrelations, and Multicollinearity}

Mean, standard deviations, alpha coefficients, and bivariate correlations are reported in Table 1 . All the variables were found to be internally reliable $(\alpha \geq .78)$. Multicollinearity was not considered to be an issue due to correlation coefficients between the imagery subscale and the other study variables ranging from low to moderate (all <.07). Moreover, none of the variables has a condition index of above 30 and a variance inflation factor of above 3 .

\section{Factorial ANOVAs}

In an effort to classify participants into meaningful age categories, two life-stage subgroups were created: middle-aged (i.e., 50-64) and older adults (i.e., 65-80). Results of the 2 sex $\times 2$ age group (50-64, 65-80) factorial ANOVAs revealed there was a significant main effect of age on self-efficacy $F(1,294)=6.41$, $p<.05, \eta \mathrm{p}^{2}=.02$, outcome expectations, $F(1,294)=13.01$, $p<.001, \eta \mathrm{p}^{2}=.04$, self-regulatory behaviors, $F(1,294)=$ $12.39, p<.001, \eta p^{2}=.04$, and enjoyment, $F(1,294)=9.43$, $p<.05, \eta \mathrm{p}^{2}=.03$.

Post hoc analyses revealed that individuals aged 50-64 years old reported greater self-efficacy $(M=62.05, S D=1.42)$, more positive outcome expectations $(M=4.10, S D=.04)$, self-regulated their behavior more $(M=2.74, S D=.06)$, and enjoyed PA significantly more $(M=5.25, S D=.10)$ than those aged $65-80$ years 
Table 1 Means, Standard Deviations, Alpha Coefficients and Correlations Matrix

\begin{tabular}{|c|c|c|c|c|c|c|c|}
\hline & 1 & 2 & 3 & 4 & 5 & 6 & $\alpha$ \\
\hline 1. Self-regulatory imagery & 1 & & & & & & .94 \\
\hline 2. Self-efficacy & $.29^{* *}$ & 1 & & & & & .83 \\
\hline 3. Barriers & -0.05 & $-.36^{* *}$ & 1 & & & & .88 \\
\hline 4. Outcome expectations & $.52^{* *}$ & $.36^{* *}$ & -0.27 & 1 & & & .94 \\
\hline 5. Self-regulation & $.59^{* *}$ & $.50^{* *}$ & $-.29^{* *}$ & $.56^{* *}$ & 1 & & .78 \\
\hline 6. Interest-Enjoyment & $.49^{* *}$ & $.50^{* *}$ & $-.35^{* *}$ & $.71^{* *}$ & $.63^{* *}$ & 1 & .94 \\
\hline 7. PA & $.22^{* *}$ & $.24^{* *}$ & -0.2 & $.23^{* *}$ & $.30^{* *}$ & $.36^{* *}$ & \\
\hline Min-max & $1-7$ & $0-100$ & $1-5$ & $1-5$ & $1-5$ & $1-7$ & \\
\hline$M$ & 4.03 & 60.76 & 1.92 & 4.03 & 2.63 & 5.12 & \\
\hline$S D$ & 1.61 & 21.00 & 0.53 & 0.53 & 0.90 & 1.42 & \\
\hline
\end{tabular}

**p $<.01$ level.

(self-efficacy: $M=55.56, S D=2.13$; outcome expectations: $M=3.86$, $S D=.05$; self-regulation: $M=2.35, S D=.09$; enjoyment: $M=4.72$, $S D=.14)$.

With regard to sex differences, the factorial ANOVAs revealed there was a significant main effect for self-efficacy, $F(1,293)=9.11, \quad p<.05, \eta p^{2}=.03$, self-regulatory behavior, $F(1,293)=11.17, p<.05, \eta p^{2}=.04$, and PA, $F(1,293)=5.49$, $p<.05, \eta \mathrm{p}^{2}=.02$. Post hoc analyses revealed that males reported significantly higher self-efficacy $(M=62.67, S D=1.82)$, selfregulated their behavior more $(M=2.72, S D=.08)$, and were significantly more physically active, $(M=5450, S D=464)$ (engaging 7 days a week in any combination of walking, moderateintensity, or vigorous-intensity activities and achieving a minimum of at least 3,000 MET-minutes/week) than females (self-efficacy: $M=54.9, S D=1.80$; self-regulation: $M=2.36, S D=.07$; PA: $M=3921, S D=458)$. Total PA score was expressed in MET-min per week as calculated by MET level $\times$ minutes of activity $\times$ events per week. There were no main effects for sex or age in imagery and perceived barriers nor were there any age $\times$ sex interactions for any of the variables. Based on these results, age and sex were included as control variables in the subsequent path analyses.

\section{Path Analysis}

In accordance with our hypotheses, regression paths were drawn from self-regulatory imagery to all social-cognitive variables (see Figure 1). The arrows represent the direction of the relationships and the signs indicate whether it is a positive or negative relationship. Specifically, direct regression paths were drawn from selfregulatory imagery to barriers, self-efficacy, outcome expectations, self-regulation, enjoyment, and PA. Direct regression paths were added from self-efficacy to both barriers and outcome expectations as well as from barriers to self-regulatory behavior and from outcome expectations to self-regulatory behavior. Finally, a direct

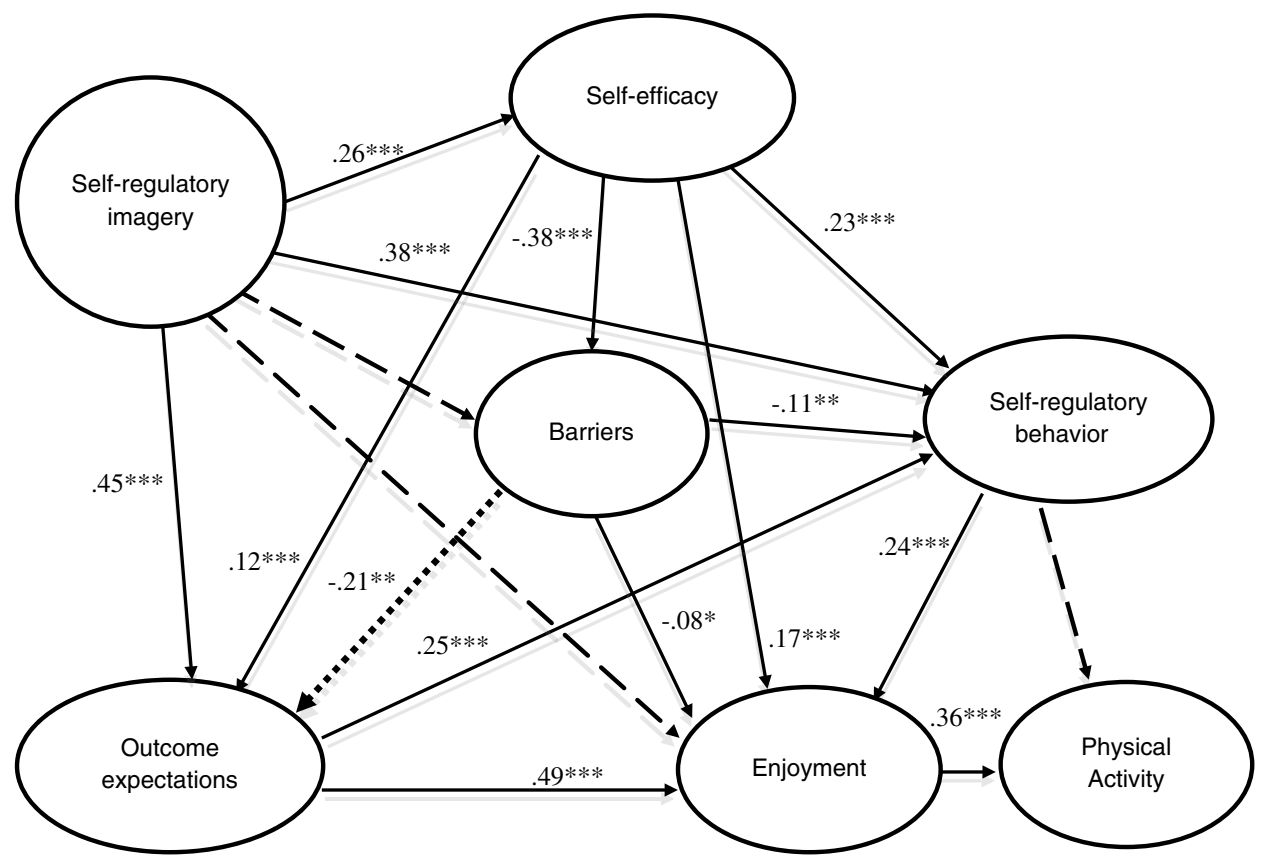

Figure 1 - Hypothesized and final model predicting PA. Note. Dashed lines were nonsignificant and were removed from the final model. The dotted line was not part of the original model but was added in the model later. For visual simplicity, age and sex control variables are not presented in this model. All coefficients are standardized. $* p<.05, * * p<.01, * * * p<.001$. 
regression path was added from self-regulatory behavior to PA and enjoyment. To control for age and sex, regression paths were also drawn from both variables to all the observed variables.

The hypothesized model showed acceptable model fit, $\chi^{2}(5)=20.77, p=.001$, by some indicators including CFI $=.98$ and $\mathrm{SRMR}=.03$. However, two commonly used indicators had poor model fit; that is, the TLI $=.86$ and $\mathrm{RMSEA}=.10$ (90\% CI $=0.06-0.15)$. Inspecting the regression weights indicated that the paths from self-regulatory imagery to both barriers $(p=.415)$ and enjoyment $(p=.177)$, as well as the path from self-regulatory behavior to $\mathrm{PA}(p=.268)$ were nonsignificant and thus removed from the model. A large modification index also suggested inserting a direct path from barriers to outcome expectations. This path was added based on research that supports barriers being inversely related to benefits of PA (Vaughn, 2009). Thus it was expected that individuals who perceive more barriers to PA would have less positive outcome expectations. The paths from age to self-regulatory behavior $(p=.065)$, enjoyment $(p=.630)$, and PA $(p=.369)$ were also removed from the model due to being nonsignificant. Finally, the paths from sex to barriers $(p=.908)$, outcome expectations $(p=.069)$, enjoyment $(p=.177)$, and PA $(p=.105)$ were also nonsignificant and removed from the model.

After making these changes, the second model provided a very good fit to the data for all indicators, $\chi^{2}(13)=18.87, p>.05$, $\mathrm{CFI}=.99, \mathrm{TLI}=.98, \mathrm{SRMR}=.03, \mathrm{RMSEA}=.04(90 \% \mathrm{CI}<0.01-$ 0.07). Inspecting the regression weights indicated that the path from self-regulatory behavior to PA remained nonsignificant $(p=.205)$ and was removed from the model. The final model revealed a similar fit to the data to the second model, $\chi^{2}(14)=21.76, p>.05, \quad \mathrm{CFI}=.99, \quad \mathrm{TLI}=.97, \quad \mathrm{SRMR}=.03$, RMSEA $=.04(90 \% \mathrm{CI}<0.01-0.08)$.

Direct and indirect effects of self-regulatory imagery. Selfregulatory imagery directly predicted self-efficacy $(\beta$ direct $=0.26$, $p=.001)$, outcome expectations $(\beta$ direct $=0.45, p=.001)$, and selfregulatory behaviors $(\beta$ direct $=0.38, p=.001)$. Self-regulatory imagery also had a total effect on self-regulatory behavior $(\beta$ total $=$ $0.57, p=.001)$, but this relationship was primarily indirect ( $\beta$ indirect $=0.19, \quad p=.001)$ through self-efficacy $(\beta$ direct $=0.23$, $p=.001)$ and outcome expectations ( $\beta$ direct $=0.25, p=.001$ ). Selfregulatory imagery had an indirect effect on perceived barriers ( $\beta$ indirect $=-0.10, \quad p=.001)$, outcome expectations $(\beta$ indirect $=$ $0.05, p=.001)$, and enjoyment $(\beta$ direct $=0.44, p=.001)$ through self-efficacy. Thus, self-efficacy mediated the relationship between self-regulatory imagery and the three social-cognitive variables: barriers, enjoyment, and outcome expectations. Also, self-regulatory imagery was indirectly related to enjoyment through outcome expectancies $($ Bindirect $=0.44, p=.001)$

Direct and indirect effects of social-cognitive variables. Selfefficacy negatively predicted perceived barriers $(\beta=-0.38$, $p=.001)$, and positively predicted outcome expectations $(\beta=0.12$, $p=.030)$, self-regulatory behavior $(\beta=0.23, p=.001)$, and enjoyment $(\beta=0.17, p=.001)$. In addition, self-efficacy was indirectly related to self-regulatory behaviors ( $\beta$ indirect $=0.09, p=.001$ ) through outcome expectancies and perceived barriers. Self-efficacy was indirectly related to PA through enjoyment ( $\beta$ indirect $=0.14$, $p=.001)$ and indirectly related to enjoyment ( $\beta$ indirect $=0.21$, $p=.001 ; \beta$ total $=0.38)$ through self-regulation and outcome expectations. Perceived barriers negatively predicted outcome expectations $(\beta=-0.21, p=.002)$, self-regulatory behavior $(\beta=-0.11$, $p=.004)$, and enjoyment $(\beta=-0.08, p<.05)$. The relationship between perceived barriers and PA was indirect ( $\beta$ indirect $=-0.08$, $p=.001)$ through enjoyment. Moreover, outcome expectations positively predicted self-regulatory behavior $(\beta=0.25, p=.001)$ and enjoyment $(\beta=0.49, p=.001)$. However, the relationship between outcome expectations and PA was indirect $(\beta$ indirect $=$ $0.20, p=.001)$ through enjoyment. Finally, self-regulatory behavior positively predicted enjoyment $(\beta=0.24, p=.001)$. Self-regulatory behavior was also indirectly related to PA ( $\beta$ indirect $=0.09, p=.001$ ) through enjoyment. In turn, greater enjoyment predicts higher levels of PA $(\beta=0.36, p=.002)$.

\section{Discussion}

This study examined the relationship between imagery use in middle-aged and older adults and PA, both directly and indirectly via social-cognitive variables. Although evidence supports the relationship between imagery, self-efficacy, and PA (Cumming, 2008), no research to date has examined the potential relationship of imagery with the social-cognitive variables of self-efficacy, outcome expectations, barriers, self-regulatory behavior, and enjoyment in middle-aged and older adults.

The impetus for assessing self-regulatory imagery via the development of a bespoke measure was based on previous research in which middle-aged and older adults highlighted the importance of self-regulating their PA behavior by committing to a routine or having a schedule, and using goals to motivate themselves to be physically active (Umstattd, Saunders, Wilcox, Valois, \& Dowda, 2006). Self-regulatory imagery was further introduced as a potential type of imagery that could act as a form of mastery experiences (Duncan et al., 2012) and as a result boost older adults' confidence in their ability to self-regulate their behavior and engage in PA. Furthermore, previous qualitative research supports that older adults use self-regulatory imagery in an exercise setting to plan their exercise moves ahead of time and achieve their exercise goals (Kosteli et al., 2017). Based on SCT and past research (Ayotte et al., 2010; Cumming, 2008), it was hypothesized that a particular form of self-regulatory imagery would be directly related to all the socialcognitive variables in the model and would positively predict PA through its association with self-efficacy, outcome expectations, barriers, self-regulatory behavior, and enjoyment.

In support, middle-aged and older adults who used images of plans and goals were found to be more confident in their ability to engage in PA and were also more likely to perceive more positive outcome expectations (e.g., better health). These results are also aligned with previous research showing that imagery can increase self-efficacy (Wesch, Milne, Burke, \& Hall, 2006) and boost outcome expectations (Hall, 1995). Imagery's role in enhancing self-efficacy is based on the idea that imagery can give individuals a sense of performance accomplishment and vicarious experience (Cumming, 2008). Similarly, when individuals imagine themselves accomplishing a certain outcome, both the outcome likelihood and the outcome value increase, and these in turn can strengthen the beliefs about the positive outcomes from engaging in PA (Hall, 1995). Overall, these results suggest that self-regulatory imagery is a potentially powerful tool for influencing exercise-related cognitions.

Higher levels of self-regulatory imagery were also associated with higher levels of self-regulatory behavior. That is, middle-aged and older adults appear to self-regulate their behavior by imagining achieving exercise goals (e.g., becoming fitter) and following an exercise plan. Previous research suggests that images of goals act as a vicarious experience for how emotionally satisfying it is to set and achieve a goal, and can influence both effort and the level of 
commitment in achieving the goals (Schultheiss \& Brunstein, 1999). Thus, self-regulatory imagery directly predicts how individuals go about setting action plans to achieve a health behavior change.

Despite the direct relationships that emerged, no direct relationship was found between self-regulatory imagery and enjoyment. Instead, the relationship was indirect through self-regulatory behavior. This finding may be due to the imagery content of plans and goals not being directly associated with affect. Thus, if the function of imagery is to increase enjoyment, it is likely that the content of planning and goal images is not fulfilling this function and may not be related to how much middle-aged and older adults enjoy PA. Consistent with the revised applied model of deliberate imagery use (Cumming \& Williams, 2012, 2013), it is important to determine whether the imagery content is personally meaningful for helping to fulfil a particular function of imagery. In this case, the content of planning and goal imagery might not help middle-aged and older adults in the purposes of achieving enjoyment. Perhaps there are other types of imagery that are more appropriate for the purposes of getting enjoyment out of PA engagement. For instance, Stanley and Cumming (2010) demonstrated that enjoyment imagery can significantly improve exercise enjoyment. Similarly, in a study with older adults, it was suggested that scenery imagery (imaging the ideal setting to exercise) can provide a positive psychological effect and make PA engagement more pleasurable (Kosteli et al., 2017). Future research should focus on using more relevant and personally meaningful imagery types to promote enjoyment in middle-aged and older adults (e.g., enjoyment imagery, scenery imagery).

Self-regulatory imagery was also found to be indirectly related with other social-cognitive variables. For instance, self-efficacy mediated the relationship between self-regulatory imagery and outcome expectations, barriers, self-regulatory behavior, and enjoyment. This finding suggests that images of plans and goals may serve to increase motivation by improving middle-aged and older adults' confidence, and this in turn will likely lead to more positive outcome expectations, less barriers, more enjoyment, and more self-regulatory behavior. A recommendation for future imagery interventions aimed at middle-aged and older adults is to target self-efficacy enhancement due to its strong role in predicting not just PA but other social-cognitive determinants that serve to maintain this behavior (White, Wójcicki, \& McAuley, 2011).

With regard to the relationships among the different socialcognitive constructs, the results indicated an association between higher levels of self-efficacy and higher levels of outcome expectations, self-regulatory behavior, and enjoyment but lower levels of PA barriers. Furthermore, self-efficacy indirectly predicted self-regulatory behavior through barriers and outcome expectations. The results are consistent with previous research (Ayotte et al., 2010; Rovniak et al., 2002) and further support the idea that raising middle-aged and older adults' self-efficacy can be associated with favorable changes in other social-cognitive variables. Collectively this research provides support for the applicability of SCT for explaining PA behavior and encourages the idea of targeting self-efficacy in imagery intervention programs to promote health behavior change.

However, contrary to our hypothesis and previous research (Anderson et al., 2006), the direct relationship between selfregulatory behavior and PA was not supported, nor was selfregulation's role as a possible mediator between self-efficacy and physical activity. Unlike most previous research, the present study incorporated enjoyment along with other social-cognitive variables into a single model and specified enjoyment as the only direct predictor of PA. Thus, higher levels of enjoyment could be related to higher levels of PA without the mediating effect of other factors. This finding confirms previous research, which shows that when middle-aged and older adults are in situations in which enjoyment is experienced, they are more likely to engage in PA (Sallis \& Owen, 1998). That is, middle-aged and older adults tend to pick and engage in physical activities for which their motivation arises within themselves, ranging from a picturesque walk in the park to playing a sport with their friends.

A plausible explanation for why self-regulation did not directly predict PA could be due to the shared variance caused by the inclusion of enjoyment in our model that reduced the total variance of self-regulation on PA. This suggests that selfregulatory behavior may be less important as social-cognitive variable when a more comprehensive model is considered. The role of enjoyment as a mediator between self-regulatory behavior and PA highlights the importance of including enjoyment in future studies. Because enjoyment is directly predicted by all the social-cognitive variables in the model, it is logical to assume that enhancing socialcognitive variables will be associated with increases in enjoyment. It is therefore important for applied practitioners who design PA interventions to encourage individuals to choose activities they enjoy. Future research might want to examine how self-regulatory imagery relates to PA, when middle-aged and older adults enjoy it versus when they do not enjoy it. Thus, middle-aged and older adults who image plans and goals are more likely to self-regulate their behavior and this leads them to enjoy PA more and it is the feeling of enjoyment that might lead them to higher levels of PA.

A limitation of the current study is that the majority of participants were aged 50-64 years old while fewer participants were above 65 years old, with only 32 participants above 70 years old. Thus, it is important to be cautious when interpreting the results, as they might be more relevant to middle-aged adults than older adults. Second, PA was assessed using the IPAQ, which although it is a valid self-report measure of PA, it has been suggested that it might over or underestimate PA levels (Lee, Macfarlane, Lam, \& Stewart, 2011; Sallis \& Saelens, 2000). Despite the debate in the literature for using objective versus self-report measures, for the purposes of our study, the use of objective methods was considered impractical for measuring the habitual PAs of a large number of people. Although objective measures are considered the gold standard for assessing PA, they are not useful with all the types of activities (Hills, Mokhtar, \& Byrne, 2014; Sallis, 2010). For instance, accelerometers might not be accurate in assessing certain activities such as swimming, cycling, and some household chores. Thus, the benefits of selfreport measures should not be overlooked (Sallis, 2010). Because PA is multidimensional in nature, using IPAQ as a self-report measure allowed for the provision of information on all the basic dimensions needed to understand PA behavior holistically (e.g., frequency, intensity, duration, and type of activity). The IPAQ is recognized as the most widely used self-report questionnaire, as it is a low-cost and easy way to tap a variety of activities in large samples, while it has been used to assess PA in almost 70 countries (Sallis, 2010). Tomioka, Iwamoto, Saeki, and Okamoto (2011) established IPAQ's validity in more than 300 adults aged 65 years and older by using an accelerometer as the criterion for PA. Future researchers should perhaps consider using objective PA measures such as accelerometers in combination with self-report measures to determine if the same relationships would emerge in this model. Furthermore, self-regulatory imagery was assessed with a newly developed six-item measure. Although the psychometric properties 
of this measure were established in the present study, with CFA indicating satisfactory overall fit indexes and adequate internal reliability, future research should continue to further validate this measure. Although the cross-sectional nature of the results does not allow us to assume causality among the different variables, the path analysis provided support for several of the proposed relationships while new relationships emerged. Thus, path analysis increased the explanatory power of the model by allowing us to test an a priori model and make hypotheses about how the different variables relate to each other (Loehlin, 2004). Because of the cross-sectional study design and the reciprocal nature of the relationships among the social-cognitive variables, some of the interpretations provided might be considered premature. However, special care was given to avoid inferring causation while looking at the relationships among social-cognitive variables in a particular order based on Bandura's SCT (1997) and previous research (Ayotte et al., 2010). Future research should re-rest these relationships and try to establish cause and effect by examining the applicability of these ideas in real-life situations (e.g., effectiveness of PA interventions).

Previous literature indicates that middle-aged exercisers seem to use multisensory images, which range from deliberate to spontaneous images (Kim \& Giacobbi, 2009). Although the amount of deliberation associated with self-regulatory imagery was not assessed in the present study, the instructions were worded in such a way that we assume that the participants reflected on deliberate imagery use (i.e., with a specific purpose in mind) as opposed to the spontaneous or unintentional images that individuals can experience in everyday life (e.g., day dreams). Future research might want to assess the extent to which older adults deliberately engaged in the various types of self-regulatory imagery. Finally, future research might want to consider older adults' ability to generate images. According to the revised applied model of deliberate imagery use (Cumming \& Williams, 2013), when designing imagery interventions it is important to account for individual characteristics such as age, sex, experience, personality, and imagery ability. These characteristics can define whether people will use imagery, what images they will use, and how they will image.

In summary, the results of the present study suggest the importance of targeting many social-cognitive variables simultaneously within the same intervention to promote PA in middle-aged and older adults. The introduction of self-regulatory imagery was found to directly or indirectly relate to all the social-cognitive constructs included in the present model, further strengthening its position as an effective strategy in modifying exercise-related cognitions and behaviors. Furthermore, our results suggested that enjoyment can differentially associate with how social cognitive variables connect to PA. That is, if middle-aged and older adults do not enjoy PA, then the effects of imagery are likely not be relevant to PA. Thus, when designing imagery interventions for middle-aged and older adults, it is important for practitioners to use imagery content that targets enjoyment combined with goal and planning images. Future research should try to replicate these results and further validate the self-regulatory imagery questionnaire.

\section{References}

Anderson, E.S., Wojcik, J.R., Winett, R.A., \& Williams, D.M. (2006). Social-cognitive determinants of PA: The influence of social support, self-efficacy, outcome expectations, and self-regulation among participants in a church-based health promotion study. Health Psychology, 25, 510-520. PubMed doi:10.1037/0278-6133.25.4.510
Arbuckle, J.L. (2012). AMOS (Version 16.0). [Computer software]. Chicago, IL: Smallwaters Corporation.

Ayotte, B.J., Margrett, J.A., \& Hicks-Patrick, J. (2010). Physical activity in middle-aged and young-old adults the roles of self-efficacy, barriers, outcome expectancies, self-regulatory behaviors and social support. Journal of Health Psychology, 15, 173-185. PubMed doi:10.1177/ 1359105309342283

Bandura, A. (1997). Self-efficacy: the exercise of control. New York, NY: W. H Freeman.

Bentler, P.M. (1995). EQS structural equations program manual. Encino, CA: Multivariate Software Inc.

Besson, H., Ekelund, U., Luan, J., May, A.M., Sharp, S., Travier, N., ... Peeters, P.H. (2009). A cross-sectional analysis of PA and obesity indicators in European participants of the EPIC-PANACEA study. International Journal of Obesity, 33, 497-506. PubMed doi:10.1038/ ijo. 2009.25

Bollen, K.A. (1989). Structural equations with latent variables. New York, NY: Wiley.

Booth, M.L., Ainsworth, B.E., Pratt, M., Ekelund, U., Yngve, A., Sallis, J.F., \& Oja, P. (2003). International PA questionnaire: 12-country reliability and validity. Medicine and Science in Sports and Exercise, 35, 1381-1395. PubMed doi:10.1249/01.mss.0000078924.61453.fb

Browne, M.W., \& Cudeck, R. (1992). Alternative ways of assessing model fit. Sociological Methods \& Research, 21, 230-258. doi:10.1177/ 0049124192021002005

Chan, C.K., \& Cameron, L.D. (2012). Promoting physical activity with goal-oriented mental imagery: A randomized controlled trial. Journal of Behavioral Medicine, 35, 347-363. PubMed doi:10.1007/s10865001-9360-6

Conn, V.S. (1998). Older adults and exercise: path analysis of self-efficacy related constructs. Nursing Research, 47, 180-189. PubMed doi:10. 1300/J013v26n03_05

Craig, C.L., Marshall, A.L., Sjöström, M., Bauman, A.E., Booth, M.L., Ainsworth, B.E., ... Oja, P. (2003). International physical activity questionnaire: 12 -country reliability and validity. Medicine \& Science in Sports \& Exercise, 35, 1381-1395. doi:10.1249/01.MSS. 0000078924.61453.FB

Cumming, J. (2008). Investigating the relationship between exercise imagery, leisure-time exercise behavior, and self-efficacy. Journal of Applied Sport Psychology, 20, 184-198. doi:10.1080/ 10413200701810570

Cumming, J., \& Williams, S.E. (2012). The role of imagery in performance. In S. Murphy (Ed.), Handbook of sport and performance psychology (pp. 213-232). New York, NY: Oxford University Press. doi:10.1093/oxfordhb/9780199731763.013.0011

Cumming, J., \& Williams, S.E. (2013). Introducing the revised applied model of deliberate imagery use for sport, dance, exercise, and rehabilitation. Movement \& Sport Sciences, 82, 69-81. doi:10. 1051/sm/2013098

Dishman, R.K., Motl, R.W., Sallis, J.F., Dunn, A.L., Birnbaum, A.S., Welk, G.J., . . Jobe, J.B. (2005). Self-management strategies mediate self-efficacy and PA. American Journal of Preventive Medicine, 29, 10-18. PubMed doi:10.1016/j.amepre.2005.03.012

Duncan, L.R., Hall, C.R., Wilson, P.M., \& Rodgers, W.M. (2012). The use of a mental imagery intervention to enhance integrated regulation for exercise among women commencing an exercise program. Motivation and Emotion, 36, 452-464. doi:10.1007/s11031-011-9271-4

Efron, B., \& Tibshirani, R.J. (1994). An introduction to the bootstrap. Monographs on Statistics \& Applied Probability. Boca Raton, FL: Chapman \& Hill.

Elavsky, S., Doerksen, S.E., \& Conroy, D.E. (2012). Identifying priorities among goals and plans: A critical psychometric reexamination 
of the exercise goal-setting and planning/scheduling scales. Sport, Exercise, and Performance Psychology, 1, 158-172. doi:10.1037/ a0028156

Enders, C.K. (2006). Analyzing structural equation models with missing data. In G.R. Hancock, \& R.O. Mueller (Eds.), Structural equation modeling: a second course (pp. 313-342). Greenwich, CT: Information Age Publishing.

Giacobbi, P., Jr., Hausenblas, H., Fallon, E., \& Hall, C. (2003). Even more about exercise imagery: A grounded theory of exercise imagery. Journal of Applied Sport Psychology, 15, 160-175. doi:10.1080/ 10413200305391

Giacobbi, P.R., Jr., Hausenblas, H.A., \& Penfield, R.D. (2005). Further refinements in the measurement of exercise imagery: The exercise imagery inventory. Measurement in Physical Education and Exercise Science, 9, 251-266. doi:10.1207/s1532784mpee0904_4.

Hair, J.F., Black, W.C., Babin, B.J., Anderson, R.E., \& Tatham, R.L. (2006). Multivariate data analysis (Vol. 6). Upper Saddle River, NJ: Pearson Prentice Hall.

Hall, C.R. (1995). The motivational function of mental imagery for participation in sport and exercise. In J. Annett, B. Cripps, \& H. Steinberg (Eds.), Exercise addiction: motivation for participation in sport and exercise (pp. 15-21). Leicester, UK: British Psychological Society.

Hausenblas, A., Hall, C., Rodgers, W., \& Munroe, K. (1999). Exercise imagery: Its nature and measurement. Journal of Applied Sport Psychology, 11, 171180. doi:10.1080/10413209908404198

Hayes, A.F. (2013). Introduction to mediation, moderation, and conditional process analysis. New York, NY: The Guilford Press.

Hills, A.P., Mokhtar, N., \& Byrne, N.M. (2014). Assessment of physical activity and energy expenditure: an overview of objective measures. Frontiers in Nutrition, 1, 5. PubMed doi:10.3389/fnut.2014.00005

Hu, L., \& Bentler, P.M. (1999). Cutoff criteria for fit indices in covariance structure analysis: Conventional criteria versus new alternatives. Structural Equation Modelling, 6, 1-55. doi:10.1080/ 10705519909540118

Jöreskog, K.G., \& Sörbom, D. (1993). LISREL 8: Structural equation modeling with the SIMPLIS command language. Chicago, IL: Scientific Software International.

Kim, B.H., \& Giacobbi, P.R. (2009). The use of exercise-related mental imagery by middle-aged adults. Journal of Imagery Research in Sport and Physical Activity, 4. doi:10.2202/1932-0191.1031

Kline, R. (2011). Principles and practices of structural equation modelling (3rd ed.). New York, NY: The Guilford Press.

Kosteli, M.C., Williams, S.E., \& Cumming, J. (2016). Investigating the psychosocial determinants of physical activity in older adults: a qualitative approach. Psychology and Health, 31(6), 730-749. PubMed doi:10.1080/08870446.2016.1143943

Kosteli, M.C., Williams, S.E., \& Cumming, J. (2017). Exploring imagery as a technique to promote physical activity in retirement. Manuscript under review.

Lee, P.H., Macfarlane, D.J., Lam, T.H., \& Stewart, S.M. (2011). Validity of the international physical activity questionnaire short form (IPAQ-SF): a systematic review. International Journal of Behavioral Nutrition and Physical Activity, 8, 115. PubMed doi:10.1186/1479-5868-8-115

Loehlin, J.C. (2004). Latent variable models: An introduction to factor, path, and structural equation analysis (4th ed.). New Jersey, NY: Lawrence Erlbaum Associates. doi:10.4324/9781410609823

Luszczynska, A., Diehl, M., Gutiérrez-Doña, B., Kuusinen, P., \& Schwarzer, R. (2004). Measuring one component of dispositional self-regulation: Attention control in goal pursuit. Personality and Individual Differences, 37, 555-566. doi:10.1016/j.paid.2003.09.026

Mathews, A.E., Laditka, S.B., Laditka, J.N., Wilcox, S., Corwin, S.J., Liu, R., . . \& Logsdon, R.G. (2010). Older adults' perceived physical activity enablers and barriers: A multicultural perspective. Journal of Aging and Physical Activity, 18, 119-40. PubMed doi:10.1249/01. MSS.0000355686.67788.99

McAuley, E. (1992). The role of efficacy cognitions in the prediction of exercise behavior in middle-aged adults. Journal of Behavioral Medicine, 15, 65-88. PubMed doi:10.1007/bf00848378

McAuley, E. (1993). Self-efficacy and the maintenance of exercise participation in older adults. Journal of Behavioral Medicine, 16, 103-113. PubMed doi:10.1007/bf00844757

McAuley, E., Duncan, T., \& Tammen, V.V. (1989). Psychometric properties of the Intrinsic Motivation Inventory in a competitive sport setting: A confirmatory factor analysis. Research Quarterly for Exercise and Sport, 60, 48-58. PubMed doi:10.1080/02701367. 1989.10607413

Moran, A. (2009). Cognitive psychology in sport: Progress and prospects. Psychology of Sport and Exercise, 10, 420-426. doi:10.1016/ j.psychsport.2009.02.010

Paivio, A. (1985). Cognitive and motivational functions of imagery in human performance. Canadian Journal of Applied Sport Sciences, $10,22 \mathrm{~S}-28 \mathrm{~S}$. Retrieved from http://europepmc.org/abstract/med/ 4085129

Preacher, K.J., \& Hayes, A.F. (2008). Asymptotic and resampling strategies for assessing and comparing indirect effects in multiple mediator models. Behavior Research Methods, 40, 879-891. PubMed doi:10. 3758/brm.40.3.879

Purdie, N., \& McCrindle, A. (2002). Self-regulation, self-efficacy and health behavior change in older adults. Educational Gerontology, 28, 379-400. doi:10.1080/03601270290081353

Resnick, B., Zimmerman, S.I., Orwig, D., Furstenberg, A.L., \& Magaziner, J. (2000). Outcome expectations for exercise scale utility and psychometrics. The Journals of Gerontology Series B: Psychological Sciences and Social Sciences, 55, S352-S356. PubMed doi:10.1093/ geronb/55.6.s352

Rhodes, R.E., \& Kates, A. (2015). Can the affective response to exercise predict future motives and physical activity behavior? A systematic review of published evidence. Annals of Behavioral Medicine, 49, 715-731. PubMed doi:10.1007/s12160-015-9704-5

Rovniak, L.S., Anderson, E.S., Winett, R.A., \& Stephens, R.S. (2002). Social cognitive determinants of physical activity in young adults: A prospective structural equation analysis. Annals of Behavioral Medicine, 24, 149-156. PubMed doi:10.1207/ S15324796ABM2402_12

Ryan, R.M. (1982). Control and information in the interpersonal sphere: An extension of cognitive evaluation theory. Journal of Personality and Social Psychology, 43, 450-461. doi:10.1037/0022-3514.43.3.450

Sallis, J.F. (2010). Measuring physical activity: practical approaches for program evaluation in Native American communities. Journal of Public Health Management and Practice, 16, 404. PubMed doi:10. 1097/PHH.0b013e3181d52804

Sallis, J.F., \& Owen, N. (1998). Physical activity and behavioral medicine (Vol. 3). London, UK: SAGE Publications.

Sallis, J.F., \& Saelens, B.E. (2000). Assessment of PA by self-report: Status, limitations, and future directions. Research Quarterly for Exercise and Sport, 71, 1-14. PubMed doi:10.1080/02701367. 2000.11082780

Salmon, J., Owen, N., Crawford, D., Bauman, A., \& Sallis, J.F. (2003). PA and sedentary behavior: A population-based study of barriers, enjoyment, and preference. Health Psychology, 22, 178. PubMed doi:10. 1037/0278-6133.22.2.178

Schultheiss, O.C., \& Brunstein, J.C. (1999). Goal imagery: Bridging the gap between implicit motives and explicit goals. Journal of Personality, 67, 1-38. doi:10.1111/1467-6494.00046 
Schuster, C., Petosa, R., \& Petosa, S. (1995). Using social cognitive theory to predict intentional exercise in post-retirement adults. Journal of Health Education, 26, 14-24. doi:10.1080/10556699.1995.10603072

Schwarzer, R., \& Fuchs, R. (1995). Changing risk behaviors and adopting health behaviors: The role of self-efficacy beliefs. Self-efficacy in Changing Societies, 259-288. doi:10.1017/cbo9780511527692.011

Shephard, R.J. (1997). Aging, physical activity, and health. Champaign, IL: Human Kinetics Publishers.

Sonstroem, R.J., Harlow, L.L., \& Josephs, L. (1994). Exercise and selfesteem: Validity of model expansion and exercise associations. Journal of Sport and Exercise Psychology, 16, 29-42. Retrieved from http://digitalcommons.uri.edu/cgi/viewcontent.cgi?article $=1004 \&$ context=psy_facpubs

Stanley, D.M., \& Cumming, J. (2010). Not just how one feels, but what one images? The effects of imagery use on affective responses to moderate exercise. International Journal of Sport and Exercise Psychology, 8, 343-359. doi:10.1080/1612197X.2010.9671957

Tabachnick, B.G., \& Fidell, L.S. (2001). Using multivariate statistics (4th ed.). Boston, MA: Allyn \& Bacon.

Tomioka, K., Iwamoto, J., Saeki, K., \& Okamoto, N. (2011). Reliability and validity of the International Physical Activity Questionnaire (IPAQ) in elderly adults: the Fujiwara-kyo Study. Journal of Epidemiology, 21, 459-465. PubMed doi:10.2188/jea.JE20110003

Umstattd, M.R., Saunders, R., Wilcox, S., Valois, R.F., \& Dowda, M. (2006). Correlates of self-regulation for physical activity among older adults. American Journal of Health Behavior, 30, 710-719. PubMed doi:10.5993/AJHB.30.6.16

Umstattd, M.R., Wilcox, S., Saunders, R., Watkins, K., \& Dowda, M. (2008). Self-regulation and PA: The relationship in older adults. American Journal of Health Behavior, 32, 115-124. doi:10.5993/ AJHB.32.2.1

Vaughn, S. (2009). Factors influencing the participation of middle-aged and older Latin-American women in physical activity: A strokeprevention behavior. Rehabilitation Nursing, 34, 17-23. doi:10.1002/ j.2048-7940.2009.tb00243.x

Wankel, L.M. (1993). The importance of enjoyment to adherence and psychological benefits from physical activity. International Journal of Sport Psychology, 24, 151-169.

Weibull, F., Cumming, J., Cooley, S.J., Williams, S.E., \& Burns, V.E. (2014). Walk this way: A brief exercise imagery intervention increases barrier self-efficacy in women. Current Psychology, 34, 1-14. doi:10.1007/s12144-014-9271-0

Wesch, N.N., Milne, M.I., Burke, S.M., \& Hall, C.R. (2006). Self-efficacy and imagery use in older adult exercisers. European Journal of Sport Science, 6, 197-203. doi:10.1080/17461390601012512

White, S.M., Wójcicki, T.R., \& McAuley, E. (2011). Social cognitive influences on physical activity behavior in middle-aged and older adults. The Journals of Gerontology Series B: Psychological Sciences and Social Sciences, 67(1), 18-26. doi:10.1093/geronb/ gbr064 


\section{Appendix 1 Self-Regulatory Imagery}

The following questions deal with imagery and exercise participation. Imagery involves "mentally" seeing yourself exercising. The image in your mind should approximate the actual physical activity as closely as possible. Imagery may include sensations like hearing the aerobic music and feeling yourself move through the exercises. Imagery can also be associated with emotions (e.g., getting psyched up or energized), staying focused (concentrating on an aerobic class and not being distracted), setting exercise plans/goals (e.g., imaging achieving a goal of losing weight), etc.
Please answer the following questions with regard to how often you use mental imagery (never to often).

1. I imagine making plans to exercise

2. I imagine the exercise goals I have set*

3. I imagine keeping to my plans for exercising*

4. I imagine being more motivated as a result of setting exercise goals ${ }^{*}$

5. I imagine making time to exercise

6. I imagine evaluating my progress towards reaching my goals

7. I imagine exercising on specific days and/or at specific times each week ${ }^{*}$

8. I imagine rewarding myself for achieving my exercise goals

9. I imagine following my exercise plan/schedule*

10. I imagine sticking to my exercise goals

11. I imagine reflecting on my exercise plans

12. I imagine achieving my exercise goals ${ }^{*}$

\begin{tabular}{ccccccc}
0 & 1 & 2 & 3 & 4 & 5 & 6 \\
Never & Rarely & Occasionally & Sometimes & Frequently & Usually & Always \\
0 & 1 & 2 & 3 & 4 & 5 & 6 \\
0 & 1 & 2 & 3 & 4 & 5 & 6 \\
0 & 1 & 2 & 3 & 4 & 5 & 6 \\
0 & 1 & 2 & 3 & 4 & 5 & 6 \\
0 & 1 & 2 & 3 & 4 & 5 & 6 \\
0 & 1 & 2 & 3 & 4 & 5 & 6 \\
0 & 1 & 2 & 3 & 4 & 5 & 6 \\
0 & 1 & 2 & 3 & 4 & 5 & 6 \\
0 & 1 & 2 & 3 & 4 & 5 & 6 \\
0 & 1 & 2 & 3 & 4 & 5 & 6 \\
0 & 1 & 2 & 3 & 4 & 5 & 6 \\
0 & 1 & 2 & 3 & 4 & 5 & 6 \\
\hline
\end{tabular}

*Items in bold are the final set of questions that were retained after CFA was performed. 